\title{
Choledochal Cyst: A Report of a Rare Disease
}

\author{
MD. BILLAL ALAM, ${ }^{1}$ SHORMISTHA BISWAS, ${ }^{2}$ RATAN DAS GUPTA, ${ }^{2}$ ANUP KUMAR SHAHA, ${ }^{3}$ SHAHIDUR RAHMAN, ${ }^{4}$ \\ PARTHA PRATIM DAS ${ }^{2}$, ASHRAFUR RAHMAN, 5 GM HAFIZUR RAHMAN, ${ }^{6}$ MOSTAKIM MARIA $^{4}$, MD KHYRUL KABIR ${ }^{7}$
}

\begin{abstract}
:
Choledochal cyst is an aneurysmal dilatation of the bile duct. It is a rare condition. Here we report a case of choledochal cyst in a 15 year-old female patient. She presented to the out patient clinic with the complaints of recurrent pain and lump in the upper abdomen along with fever for I year. The diagnosis was made by abdominal ultrasound complemented by computed tomography.
\end{abstract}

Keyword: Choledochal cyst, Todani classification, CT of abdomen, Roux-en Y hepaticojejunostomy.

\section{Introduction:}

Choledochal cyst is an aneurysmal dilatation of the bile duct involving the extrahepatic biliary radicles, the intrahepatic biliary radicles, or both. In 1723, Vater and Ezler published the anatomical description of a choledochal cyst. It is a rare condition with an incidence between 1:100.000 and 1:150.000 live births in the developed countries; although it is more common in the developing countries. ${ }^{1}$ It is 100 times more common in Japan than other developed countries with an estimated incidence of 1:1000. ${ }^{2-3}$ These congenital lesions have a female:-male preponderance of $4: 1{ }^{4}$ Presentation with the classic triad of pain, jaundice, and an abdominal mass occurs rarely. ${ }^{5}$ Here we report a case of choledocal cyst with classical triad of presentations.

\section{Case Report:}

A 15 years old girl was admitted into DMCH with the complaints of recurrent pain and lump in the upper abdomen with fever for 1 year. Pain first appeared about one year back which was sudden, severe, localized, cramping, aggravated by taking food and relieved by taking analgesics. Initially pain lasted for 3 days and was associated with high grade, intermittent fever with chills and rigors subsided by taking antipyreticss. Pain was also associated with several episodes of vomiting. She noticed a lump on her right upper abdomen which has been gradually increasing in size for last 1 year. She developed yellow coloration of sclera and urine associated with generalized itching and passage of pale stool. It lasted for 1 month and was associated with low grade irregular fever with evening rise of temperature without any chills and rigors and subsided by taking analgesics. Thereafter she had several episodes of sudden, dull aching, localized right upper abdominal pain persisting for few hours and relieved spontaneously. The pain was associated with low grade irregular fever without chills and rigors and subsided by taking analgesics.

On general examination, she was not anaemic and non icteric . Her vital signs were within normal limit. Lymph nodes were palpable in right submandibular region and in both posterior cervical chains 1 to 2 in number, largest one was in left posterior cervical chain about $1 \mathrm{~cm}$ in diameter, discrete, firm, nontender and mobile.Her abdominal examination revealed a mass in the right hypochondriac,epigastric and part of left hypochondriac regions about $13.5 \mathrm{~cm}$ from right subcostal margin along midclavicular line, mildly tender, moved with respiration, smooth, firm with rounded margin, dull on percussion and there was no bruit. Shifting dullness was negative. Examination of all other systems revealed no abnormality.

Investigations revealed $\mathrm{Hb} 10 \mathrm{gm} / \mathrm{dl}$, TC $5670 / \mathrm{cmm}$, Platelets count was 2, 68,000/cmm, ESR: $65 \mathrm{~mm}$ in $1^{\text {st }}$ hour. PBF showed nonspecific findings. Liver function test showed serum bilirubin $1.6 \mathrm{mg} / \mathrm{dl}$, SGPT: $40 \mathrm{U} / \mathrm{L}$, Alkaline Phosphatase: 2015 U/L, PT: $13.0 O$ sec. MT test, sputum for AFB and ICT for kalaazar was negative. Left cervical lymph node biopsy showed nonspecific changes. Other routine tests were normal.

The Initial diagnosis was made on the basis of an abdominal ultrasound which showed grossly dilated intrahepatic biliary

1. Associate Professor, Department of Medicine, DMCH, Dhaka

2. Assistant Professor, Department of Medicine, DMCH, Dhaka

3. Associate Professor, Department of Medicine, SSMC, Dhaka

4. Intern Doctor, DMCH, Dhaka

5. Assistant Registrar, Department of Medicine, DMCH, Dhaka

6. Indoor Medical Officer, Department of Medicine, DMCH, Dhaka

7. Post graduate trainee, Department of Medicine, DMCH, Dhaka

Correspondence: Md. Shahidur Rahman, Intern Doctor, DMCH, Dhaka, Email:shaheddmc@ gmail.com. 
channels with multiple intercommunicating cystic areas of different sizes in the region of CBD and other extrahepatic biliary tree. Diagnosis was confirmed by an abdominal computerized tomography which showed enlarged liver with grossly dilated Intrahepatic biliary channels with multiple inter-communicating cystic areas of different sizes along the line of CBD, largest one was $12 \mathrm{X} 10 \mathrm{X} 9 \mathrm{~cm}$. Spleen was mildly enlarged in size.

Finally our diagnosis was choledochal cyst type IVa and we referred the patient to Hepato-Biliary surgeons for further management.

Abdominal CT showing multiple intrahepatic hypodense areas indicating multiple cysts in Figure 1 and a large extrahepatic cyst in the CBD region in Figure 2.

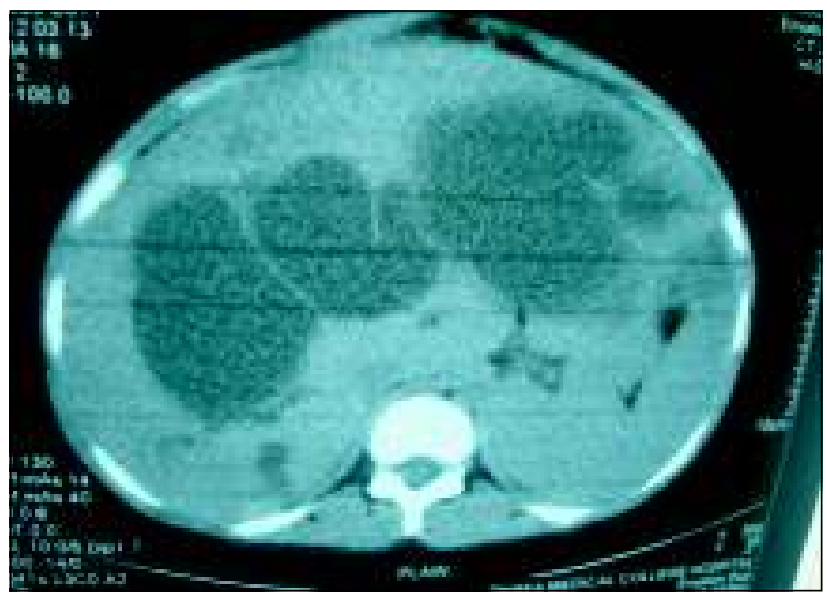

Fig.-1

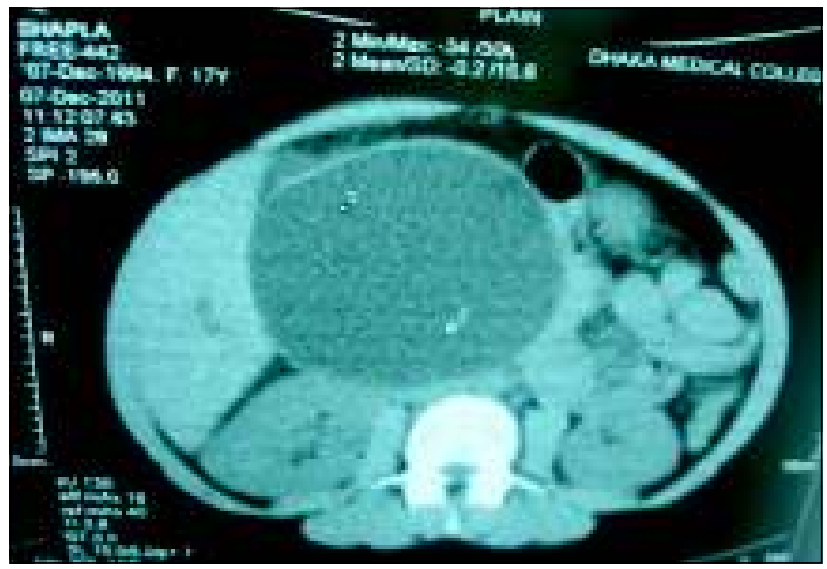

Fig.-2

\section{Discussion:}

Choledochal cysts are congenital conditions involving cystic dilatation of bile ducts ${ }^{6}$. The vast majority of patients with choledochal cyst have an anomalous junction of the CBD with the pancreatic duct. An anomalous pancreatic bile duct junction (APBJ) is characterized when the pancreatic duct enters the $\mathrm{CBD} 1 \mathrm{~cm}$ or more proximal to where the CBD reaches the ampulla of Vater. The APBJ allows pancreatic secretions and enzymes to become activated; this results in inflammation and weakening of the bile duct wall. Severe damage may results in complete denuding of the CBD mucosa ${ }^{6}$. Choledochal cysts may be presented with abdominal pain which is the most common symptoms, attack of jaundice of obstructive type and a palpable mass in the right hypochondrium, this is typically cystic. ${ }^{7}$

The classic triad of pain, jaundice, and an abdominal mass occurs in only $6 \%$ of cases. ${ }^{8-9}$

They were classified into 5 types by Todani in $1977 .{ }^{9}$

Classification was based on site of the cyst or dilatation. Type I to IV has been subtyped.

- $\quad$ Type I: Most common variety (80-90\%) involving saccular or fusiform dilatation of a portion or entire common bile duct (CBD) with normal intrahepatic duct.

- $\quad$ Type II: Isolated diverticulum protruding from the CBD.

- $\quad$ Type III or Choledochocele: Arise from dilatation of duodenal portion of $\mathrm{CBD}$ or where pancreatic duct meets.

- $\quad$ Type IVa: Characterized by multiple dilatations of the intrahepatic and extrahepatic biliary tree.

- Type IVb: Multiple dilatations involving only the extrahepatic bile ducts.

- $\quad$ Type V or Caroli's disease: Cystic dilatation of intra hepatic biliary ducts.

Pathologically the cyst wall is composed of fibrous tissue with interspersed elastic and sparse smooth muscle fibers, the internal lining consists of columnar epithelium but it is often destroyed by inflammation and the pressure of the distending fluid.${ }^{10}$ So the choledochal cyst is devoid of epithelium and the wall is fibrous and fails to contract, leading to poor emptying and significant bile stasis. ${ }^{11}$

Ultrasonography is the best initial investigative study, and the ultrasound findings are diagnostic in many patients and it can help in detecting associated conditions and complications of choledochal cysts such as choledocholithiasis, intrahepatic biliary dilatation, portal vein thrombosis gall bladder or biliary neoplasms, pancreatitis and hepatic abscess. ${ }^{11}$

In most patients a complimentary study is necessary including CT scanning and magnetic resonance imaging (MRI), which provide detailed information concerning the 
relationship between the lower end of the bile duct and the pancreatic duct. Cholangiography is absolutely essential to delineate the biliary anatomy accurately, so ERCP or PTC can define the extent of the disease. ${ }^{12}$ But in our case we did not perform Cholangiography, ERCP or PTC as the patient was poor and we could not do any surgery.

The complications of choledochal cyst include recurrent cholangitis and pancreatitis, hepatic abscess formation and calculus disease. ${ }^{13}$ In our patient other than cholangitis none of these complications happened most probably due to free passage of bile to duodenum, with no elements of stagnation and cholangitis.

If left untreated choledochal cyst produces liver damage, which progress to biliary cirrhosis and portal hypertension with all its sequelae. ${ }^{14}$

The anomaly is premalignant and usually develops in the postero medial wall of the cyst. Most patients are in their thirties and $75 \%$ of tumors are adenocarcinoma although squamous cell carcinoma and cholangio-carcinoma may occur. Malignancy in choledochal cyst may reach $10 \%$ in some series. 15

Once diagnosed the choledochal cyst should be treated surgically. Careful identification and protection of the orifice of the pancreatic duct is mandatory.

Type I cysts need resection and reconstruction of the bile duct by means of hepatico-jejunostomy with a Roux-en-Y segment of jejunum joined to the common hepatic duct above the cyst. 13

Type II cyst can be usually excised the defect in the C.B.D being repaired by primary suture over a T-tube brought out through a separate incision in the duct.$^{14}$ Type III cyst can be partially excised and opened into the duodenum by mean of either a trans-duodenal sphincteroplasty or endoscopic sphincterotomy ${ }^{10}$.

Rest of the types including our diagnosis type- IVa constitute a difficult management problem and may require segmental resection of the liver particularly if there are intra hepatic stones, strictures or abscesses as well as an extra hepatic cyst, hepatico jejunostomy is then necessary to reconstitute the biliary drainage. Even Partial or complete hepatectomy with subsequent liver transplantation maybe needed.

The prognosis for most patients with cysts of the extra hepatic bile duct, appropriately resected and reconstructed is excellent but for our case prognosis is bad.

\section{Conclusion:}

Although choledochal cyst is a benign disease it can present with life threatening complications. Early suspicion of this rare disease is important because surgical treatment is the only way to avoid the dramatic complications of this disease. So to prevent cost-intensive and potentially life-threating complications, a choledochal cyst must be considered in the differential diagnosis whenever the rather common diagnosis of a hepatic cyst is considered.

\section{Conflict of Interest : None}

\section{References:}

1. Mann CV, Russell RCG. Gall bladder and bile duct. In: Russell RCG, editor. Bailey and Love short practice of surgery. 23rd edition, Chapman and Hall London 2000; 46: 973-994.

2. Mujano T, Yamataka A: Choledochal cyst. Curr Opin Pediatr 1997, 9(3):283-288.

3. Shi LB, Peng SY, Meng XK, et al.: Diagnosis and treatment of congenital choledochal cyst: 20 years' experience in China. World J Gastroenterol 2001; 7(5):732-734.

4. Powell CS, Sawyers JL, Reynolds VH. Management of adult choledochal cysts. Ann Surg. 1981; 193:666-76.

5. Crittenden SL, Mekinley MJ. Choledochal cystclinicalfeatures and classification. Am J Gastroenterol 1985; 80: 643-647

6. Choledochal cyst" at Dorland's Illustrated Medical Dictionary 31 st edition, page: 466 .

7. Morris PJ, Wood C. The Billiary tract. In: Moris PJ, Wood C, editors. Oxford text book of surgery, 2nd edition, oxford 2000; II (31): 1668-1670.

8. Powell CS, Sawyers JL, Reynolds VH. Management of adult choledochal cysts. Ann Surg. 1981; 193:666-76.

9. Crittenden SL, Mekinley MJ. Choledochal cystclinicalfeatures and classification. Am J Gastroenterol 1985; 80: 643-647.

10. O'neill J, Tempelton JA, Schanter JM, et al. Recent experience with choledochal cyst. Ann Surg 1985; 53: 205-207.

11. Liu CL, Fan ST, Chung-Mau, Lo CM, et al. Choledochal cyst in adults. Arch Surg 2002; 137(4): 465-468.

12. Vander PD, Lane B, Wetal WJ. Choledochal cysts. Surg Genecol Obstet 1988; 167: 447.

13. Metcalfe MS, Wemyss-Holden SA, Maddern GJ. Management Dilemmas with Choledochal cyst. Arch Surg 2003; 138(3): 333-339.

14. Annal of Royal College of Surgeons of England (1990) volume 72/229-235.

15. Jan YY, Chen HM, Chen MF. Malignancy in Choledochal cyst. Hepatogastronenterlogy 2002; 49(43): 100-103. 